\title{
Presentation and Management of Wilm's Tumour in Sudan (Three Centre Experience from 2014-2016)
}

\section{Ahmed Mohammed Atiaallah" ${ }^{*}$, Mutaz Ogeal Osman', Aamir Abdallah Hamza², Mawadda Farah ${ }^{3}$, Omer Alamin 4}

${ }^{1}$ Faculty of Medicine, Red Sea University, Port Sudan, Sudan

${ }^{2}$ Faculty of Medicine, University of Bahri, Khartoum Bahri, Sudan

${ }^{3}$ Sudan Medical Specializations Board, Khartoum, Sudan

${ }^{4}$ National Elribat University Hospital, Khartoum, Sudan

Email: *Mr.ahmedatia85@gmail.com

How to cite this paper: Atiaallah, A.M., Osman, M.O., Hamza, A.A., Farah, M. and Alamin, O. (2021) Presentation and Management of Wilm's Tumour in Sudan (Three Centre Experience from 2014-2016). Open Journal of Urology, 11, 358-366. https://doi.org/10.4236/oju.2021.1110035

Received: September 6, 2021

Accepted: October 26, 2021

Published: October 29, 2021

Copyright $\odot 2021$ by author(s) and Scientific Research Publishing Inc. This work is licensed under the Creative Commons Attribution International License (CC BY 4.0).

http://creativecommons.org/licenses/by/4.0/

(c) (i) Open Access

\begin{abstract}
Background: Wilm's tumour is a cancer of the kidneys that typically occurs in children younger than fifteen years of age and rarely in adults. With an early diagnosis and proper management of Wilm's tumour by Multi-modal approach, excellent outcome can be obtained. This study was designed to reflect the clinical presentations and focus on different management modalities with an outcome of Wilm's tumour in Sudan. Patients and methods: This descriptive, retro-prospective analytic study included all patients of Wilm's tumour at Soba University Hospital, Gezira national paediatric surgery centre and Khartoum teaching Hospital from January 2014 to January 2016. Results: Thirty patients (pts) were included. Females were predominant in a ratio of 3 : 1 to males. The mean age was 3.0 - 5.9 years. Those who came from central and western of Sudan were more affected. Most patients presented with abdominal mass 28 pts (93.3\%), followed by abdominal distension in 16 pts (53.3\%), while the less frequent presentation was haematuria seen only in 2 pts (6.7\%). The multimodal approach: surgery and chemotherapy used in 21 pts $(70 \%)$ and single modality was used in nine patients: surgery alone in 6 pts $(20 \%)$, or chemotherapy alone in 3 pts $(10 \%)$. The patients discharged uneventfully 23 pts (76\%). Morbidity was seen in two patients. Deaths were occurred in five patients in the study (16.7\%). Conclusion: The finding of this study reflected that Wilm's tumour has an excellent outcome when patient was managed by multimodal approach.
\end{abstract}




\section{Keywords}

Wilm's Tumour, Multi-Modal Approach, Nephrectomy, Chemotherapy, Outcome

\section{Introduction}

Wilm's tumour is a malignant tumour originating in the cells of the kidney and one of the common renal tumour that primarily affects children and rare adult [1], and also known as nephroblastoma. Wilm's tumour may arise in either or both kidneys. The condition is named after DR. Max Wilm's, the German surgeon in $19^{\text {th }}$ century (1867-1918) who first described it [2]. He is recognized that the cancer develops from immature kidney cells. It is made up of cells that are significantly immature and abnormal. These cells are also capable of invading nearby structures within the kidney and travelling out of the kidney into other structures. Malignant cells can even travel through the body to invade other organ systems, most commonly the lungs and brain. These features of Wilm's tumour make it a type of cancer that, without treatment, would eventually cause death. However, advances in medicine during the last 20 years have made Wilm's tumour a very treatable form of cancer [3] [4]. Treatment is a living example of success achieved through a multidisciplinary collaboration of the National Wilm's Tumour Study Group (NWTSG) and the Societe Internationaled Oncologie Pediatrique (SIOP) [5] [6].

Pathogenesis of Wilm's tumor: Most cases of Wilms tumor are not caused by inherited genetic factors and do not cluster in families. Approximately 90 percent of these cancers are due to somatic mutations, which means that the mutations are acquired during a person's lifetime and are present only in the tumor cells. Mutations that are present in cells throughout the body (called germline mutations) are responsible for the remaining 10 percent of Wilms tumor cases and cause either Wilms tumor without any other signs or symptoms or syndromes in which Wilms tumor is one of multiple features. These cases follow autosomal dominant inheritance, which means one copy of the altered gene in each cell can cause a Wilms tumor-related syndrome or increase a person's chance of developing the cancer alone. Most of these cases result from new (de novo) mutations in the gene that occur during the formation of reproductive cells (eggs or sperm) or in early embryonic development. The AMER1 gene is located on the $\mathrm{X}$ chromosome (one of the two sex chromosomes), so when Wilms tumor is caused by mutations in this gene, the condition follows an $\mathrm{X}$-linked dominant pattern. In females (who have two $\mathrm{X}$ chromosomes), a mutation in one of the two copies of the gene in each cell is sufficient to increase a person's chance of developing cancer. In males (who have only one X chromosome), a mutation in the only copy of the gene in each cell increases their cancer risk. In many cases, the genetic basis for Wilms tumor and the mechanism of 
inheritance are unclear [7].

\section{Patients and Methods}

This study was conducted in Khartoum Teaching Hospital (KTH), Soba University Hospital (SUH), Gezira National centre of paediatric surgery (GNCP) in Sudan in two years' period from January 2014-January 2016. All patients in these centres were diagnosed with Wilm's tumour included. Total of thirty patients met the criterion of inclusion were studied for different clinical presentations, focusing on management modalities, duration of hospital stayed and outcome observed up to seven months.

\section{Results}

A total of 30 patients with Wilm's tumour, who satisfied the inclusion criteria were studied. There is female predominant 18 pts $(60 \%)$ while male $12(40 \%)$, with male to female ratio of $1: 3$. Most of the patients 11 (36.7\%) were in the age group 3.0 - 5.9 years, whereas those more than 6 years were only 5 pts (16.7\%) and patients of less than one-year age were only 6 pts (20\%). Most of the patients were from either Central or Western part of Sudan 14 pts (46.7\%) and 10 pts (33.3\%) respectively, four patients came from East (13.3\%) and only two patient form north of Sudan (6.7\%). Most of the patients presented by abdominal mass $28(93.3 \%)$ patients and some of them associated with abdominal distension in $16(53.3 \%)$ patients. While the less frequent symptoms over all is blood in urine seen only in 2 pts (6.7\%) (Table 1). Twenty-two patients (73.3\%) presented in five weeks or less However $6(20 \%)$ of patients presented after the $10^{\text {th }}$ week. The commonest clinical sign was abdominal mass seen in almost 29 pts (96.7\%), followed by anaemia in 8 pts (26.7\%), while less frequent was haematuria seen in 3 pts (10\%), organomegaly in 4 patients (13.3\%) and hypertension in 1 patient (3.3\%).

The investigations modalities needed to confirm the diagnosis and determine the extent and effect of the disease. Radiological investigations (Computed tomography scan and abdominal ultrasounds scan) were done in $93.3 \%$ and $73.3 \%$

Table 1. Presenting symptoms of patients with Wilm's tumour in the study.

\begin{tabular}{ccc}
\hline Symptoms & Frequency & Percent \\
\hline Abdominal mass & 28 & 93.3 \\
Abdominal pain & 07 & 23.3 \\
Abdominal distension & 16 & 53.3 \\
Fever & 09 & 30.0 \\
Nausea & 04 & 13.3 \\
Vomiting & 06 & 20.0 \\
Anorexia & 07 & 23.3 \\
Blood in the urine & 02 & 6.7 \\
\hline
\end{tabular}


respectively, laboratory investigations were done also (60\% - 97\%), and confirmatory tissue biopsy: true cut needle biopsy (TCNB), excisional biopsy and incisional biopsy in $60 \%$. There are multi-modal protocols for treatment of Wilm's tumour in the study. In soba hospital the protocol of treatment is preoperative chemotherapy followed by surgery (nephrectomy), while Khartoum teaching hospital and Gezira National centre of paediatric surgery treated their patients by surgically (nephrectomy) first followed by postoperative chemotherapy. In the study multi-modal approach surgery (nephrectomy) and chemotherapy used in 21 pts (70\%), while single modality was used in 9 patients: surgery (nephrectomy) alone in 6 pts (20\%) and chemotherapy alone in 3 pts (10\%). The mean duration of hospital stay was $4.0 \pm 4.2$ week (range 1 - 15 weeks). Most of patients 22 pts (73.3\%) discharged within five weeks. Wilm's tumour patients who stayed in hospital four more than $10^{\text {th }}$ week only 2 pts $(6.7 \%)$. The majority of patients were discharged uneventfully 23 pts (76\%). Morbidity was seen in two patients one of chronic renal failure and other with intraabdominal haemorrhage. Deaths were occurred in five patients in the study (16.7\%). The outcome was good in patients presented earlier. Patients presented in five weeks or less, had uneventful discharge in $18 / 22(81.8 \%)$ and $13.6 \%$ mortality rate, whereas those presented eleven weeks or more, had uneventful discharge in $3 / 6(50 \%)$ and $33.3 \%$ mortality rate, but the difference is not statistically significant, $p$ value 0.492 (Table 2). Twenty-one patients had multimodal treatment (surgery and chemotherapy) 18 (85.7\%) were discharged uneventfully, morbidity in $1(4.8 \%)$ and there were two mortalities (9.5\%). Six patients underwent surgery (nephrectomy) alone: one third of them died 2 pts (6\%). Three patients had received chemotherapy alone: one was discharge in good condition, one developed complication and the third case died. There no relation of statistical significance found in this study between treatment modalities and outcome, p value 0.209 (Table 3). The follow up was short term up to ten weeks (mean; $3.4 \pm 2.7$ weeks). The follow up durations in most of patients between $1-3$ months 19 pts (63.3\%), and less frequent follow-up period is less than one month only 1 pts (3.3\%).

\section{Discussion}

Wilm's tumour is second common solid abdominal paediatric malignancy and the commonest type of renal tumour in children. Internationally the outcome of

Table 2. Duration of the illness and outcome of treatment.

\begin{tabular}{ccccc}
\hline \multirow{2}{*}{$\begin{array}{c}\text { Duration } \\
\text { (weeks) }\end{array}$} & Uneventful & Complication & Death & Total \\
\cline { 2 - 4 } & $18(81.8 \%)$ & $1(04.5 \%)$ & $3(13.6 \%)$ & $22(100 \%)$ \\
$1-5$ & $02(100 \%)$ & $0(0.0 \%)$ & $0(0.0 \%)$ & $02(100 \%)$ \\
$6-10$ & $03(50.0 \%)$ & $01(16.7 \%)$ & $02(33.3 \%)$ & $06(100 \%)$ \\
$11+$ & $\mathbf{2 3 ( 7 6 . 7 \% )}$ & $\mathbf{0 2 ( 0 6 . 7 \% )}$ & $\mathbf{0 5}(\mathbf{1 6 . 7 \% )}$ & $\mathbf{3 0 ( 1 0 0 \% )}$ \\
Total & & &
\end{tabular}

$\mathrm{p}$ value 0.492 . 
Table 3. Modalities of treatment and outcome in patients with Wilm's tumour in the study.

\begin{tabular}{ccccc}
\hline \multirow{2}{*}{ Outcome } & \multicolumn{3}{c}{ Treatment } & \multirow{2}{*}{ Total } \\
\cline { 2 - 4 } & Surgery & Chemotherapy & Chemotherapy and surgery & \\
\hline Uneventful & 4 & 1 & 18 & 23 \\
Complication & 0 & 1 & 01 & 02 \\
Death & 2 & 1 & 02 & 05 \\
Total & $\mathbf{6}$ & $\mathbf{3}$ & $\mathbf{2 1}$ & $\mathbf{3 0}$ \\
\hline
\end{tabular}

p value 0.209 .

Wilm's tumour has significantly improved in the last two decades after adopting multi-modal approach in management of the disease in most of centre. In Sudan, the Wilm's tumour is also one of the most common abdominal malignancies children as showed by Hassan Ibrahim and Hatim Khalil studies [8] [9].

In this study, thirty patients whom satisfied the inclusion criteria were studied. The main age of most patients in the study was between 3.5 to 5.9 years. It was similar to studies done in Sudan by Abuidris DO et al., and Eiman Zaki Antoun. [10] [11] In Kenya the study done by Rogers T et al., in south Africa by Abdallah, F. K and Macharia W. M [12] [13] and internationally Green DM et al. [14] all of them have similar main age to this study. In the study the female is commonly affected by disease with male to female ratio of 1:3 which is increasing than 0.9:1 reported earlier in Sudan [10] [11] [15] and also compared to study in Pakistan by Fadoo $\mathrm{Z}$ et al. revealed that male to female ratio of 1.5:1 the median age of presentation was 4 years, [16] the reverse of this ratio is seen in Indian studied by Green DM et al. that showed: male to female ratio of 3:1 [17].

Most of the patients came from centre and west of Sudan 14 (46.7\%), 10 (33.3\%) patients respectively, this was compared to Sudanese study done by Salih HM between 2006 and 2010 at Khartoum university resulted in Forty two percent of patients were from western Sudan, 4 (13.3\%) form east and the least from north of Sudan 2 (6.7\%) patients [15]. This is similar result to two other studies done in Sudan: first by Eiman Zaki Antoun [11], second study was done by Hassan Ibrahim on 2013 conducted in Khartoum teaching hospital and Soba university hospital [8]. Regarding the clinical presentations most of the patients in the study presented by abdominal mass 28 pts (93.3\%), this is also similar to last study in Sudan done by Abuidris DO et al. reported that abdominal mass is common presentation of the disease in Sudan [10], also that matched with study done in south Africa by Rogers T et al. [12] and international by reported study by Green DM [18]. Also most of symptoms and signs in the study were similar in both, Sudan and international comparisons [18]. The abdominal mass associated with abdominal distension in $16(53.3 \%)$ patients, while the abdominal pain was the less frequent abdominal symptom seen in 7 (23.3\%) of the patients, anoxia presented in only 7 (23.3\%) patients and the least frequent symptoms over all is blood in urine seen only in $2(6.7 \%)$ patients. In this study the most frequent 
duration of the symptoms was ranged from 1 - 5 weeks 22 (73.3\%) patients. And less frequent between 6 - 10 weeks only 2 (6.7\%) patients. From 11 weeks and more, 6 (20\%) patients presented in this period of time. Regarding duration of symptoms, I didn't find any previous studies in Sudan approved the accurate duration of the symptoms before presented to hospital.

In the study most useful tool in diagnosis of Wilm's tumour is radiological Imaging: ultrasound scan was firstly described in most of patients $22(73.3 \%)$, then computed tomography scan was used in almost 28 (93.3\%) patients, to confirm the diagnosis and to assist evaluating the extension and invasion of Wilm's tumour. In Routine investigations the most useful was the following: low haemoglobin level is noticed in $12(40 \%)$ patients while normal in 18 (60\%) patients, haematuria seen in only 3 pts (10\%) of urine analysis, blood urea and serum creatinine were noticed to be raised in only one $(3.3 \%)$ and Liver function tests was not routinely used so it was requested to only 14 patients with 3 (10\%) patients showed abnormality. All this data regarding the diagnostic work up were similar to international data reported by study of Green DM [19].

Confirmatory diagnosis of Wilm's tumour after high suspicion with biopsy was remained controversial, so biopsy is used in most of the study 18 pts (60\%), biopsy is taken either: TCNB which is used in $9(30 \%)$ patients, excisional biopsy in 7 (23.3\%) patients and incisional biopsy only used in $2(6.7 \%)$ patients. Different types of biopsy were taken according to each centre protocol: in SUH the TCNB is preferable option for diagnosis of Wilm's tumour firstly before starting the treatment, while KTH and GNCP used imaging to diagnosis before nephrectomy (excisional biopsy) was done, and all centres didn't use incisional biopsy except in inoperable cases for pathological diagnosis to start the palliative treatment. In comparison to international protocol there were two different accepted protocols regarding biopsy in patient with Wilm's tumour as follow: In North America, patients with suspected Wilm's tumour undergo nephrectomy first. In contrast to most European centres who make a presumptive diagnosis of Wilm's tumour based on imaging findings alone. Clinicians in Europe prefer to administer chemotherapy before nephrectomy without survival compromise as seen by study of Green DM et al., at 1994 and 2004 [17]. Transcutaneous biopsy is not usually recommended and may in fact complicate the treatment by causing preoperative tumour spill, requiring whole abdominal radiotherapy as reported by Green DM et al., 1994 [14] [17].

There were different treatment modalities in the study: surgery followed by chemotherapy was used in most of patients $21(70 \%)$, while surgery alone used in $6(20 \%)$ patients and the least used protocol is chemotherapy alone $3(10 \%)$ patients this only used in an inoperable case. So KTH and GNPC the management protocols were all for operable patients' undergoing surgery (nephrectomy) followed by postoperative chemotherapy, while in SUH they used preoperative chemotherapy followed by nephrectomy. All Sudanese centres used the biopsy then chemotherapy in inoperable cases. This match the study in Nigeria study done by Uba AF and Chirdan LB revealed that the protocol of Nephrect- 
omy and chemotherapy were the best modality of treatments [20]. In compared to International studied by Ruteshouser et al. the protocol of Children's Oncology Group (COG) was usual approach is nephrectomy followed by chemotherapy, with or without postoperative radiotherapy [13]. Also six patients in the study treated with nephrectomy alone, this met evidence suggests that certain children with stage I disease with favourable histology do well with nephrectomy alone as reported by Ruteshouser et al., 2008 [21].

In this study, the outcome of Wilm's tumour is excellent. Uneventful discharged with good outcome was seen in 18 pts (60\%), morbidity showed in only 2 pts (6.7\%) and death or unknown outcome was seen in similar number of patients in 5 pts (16.7\%). Internationally approximately $80 \%-90 \%$ of children with a diagnosis of Wilm's tumour survive with current multimodality therapy as reported in study of Pelletier J et al. [12] Morbidity was seen in two patients. Deaths were occurred in five patients in the study (16.7\%). Most of patients in the study continued to be followed up to first three months 19 (63.3\%) patients, the least frequent follow-up period was less than one month only $1(3.3 \%)$ patients and between 4 - 6 months and more than 7 months had been seen in 6 (20\%) patients, 4 (13.3\%) patients respectively.

\section{Conclusions}

Wilm's Tumor in Sudan has similar clinical presentations compared to international reported data. The most approached tools for diagnosis are ultrasound scan and computed tomography and also no needed for biopsied except in advanced stages of disease. Wilm's tumor in Sudan has an excellent outcome when children are managed by multimodal approach: namely nephrectomy followed by adjuvant chemotherapy.

\section{Recommendations}

Multimodal approach is the costive but only method to achieve the excellent outcome in treating this cancer, so I raise this issues to Sudan government to build special pediatric oncology centers to enhance cancer outcome.

\section{Conflicts of Interest}

None.

\section{References}

[1] Ganesh, S., Vennila, J.J. and Scholz, H. (2011) An Overview and Perspectives of Wilm's Tumour. International Journal of Cancer Research, 7, 1-7. https://doi.org/10.3923/ijcr.2011.1.7

[2] Raffensperger, J. (2015) Max Wilm's and His Tumour. Journal of Paediatric Surgery, 50, 356-359. https://doi.org/10.1016/j.jpedsurg.2014.10.054

[3] American Cancer Society. https://www.cancer.org

[4] Petrini, J., Damus, K., Russell, R., Poschman, K., Davidoff, M.J. and Mattison, D. (2002) Contribution of Birth Defects to Infant Mortality in the United States. Tera- 
tology, 66, S3-S6. https://doi.org/10.1002/tera.90002

[5] Coppes, M.J. and Egeler, R.M. (1999) Genetics of Wilm's Tumour. Seminars in Urologic Oncology, 17, 2-10.

[6] Davies-Johns, T., Chidel, M. and Macklis, R.M. (1999) The Role of Radiation Therapy in the Management of Wilm's Tumour. Seminars in Urologic Oncology, 17, 46-54.

[7] Tian, F., Yourek, G., Shi, X. and Yang, Y. (2014) The Development of Wilms Tumor: From WT1 and MicroRNA to Animal Models. Biochim Biophys Acta, 1846, 180-187. https://doi.org/10.1016/j.bbcan.2014.07.003

[8] Ibrahim, H. (2013) Pattern and Clinical Profile of Paediatric Abdominal Tumour at Khartoum Teaching Hospital and Ribat University Hospital. MD Thesis, Sudan Medical Specializations Board, Sudan.

[9] Hatim, K. (2013) Pattern of Presentation of Abdominal Mass in Paediatrics Patients in Soba University Hospital from January 2010 to January 2012. MD Thesis, Sudan Medical Specializations Board, Sudan.

[10] Abuidris, D.O., Elimam, M.E., Nugud, F.M., Elgaili, E.M., Ahmed, M.E. and Arora, R.S. (2008) Wilm's Tumour in Sudan. Paediatrics Blood Cancer, 50, 1135-1137. https://doi.org/10.1002/pbc.21547

[11] Zaki Antoun, E. (1992) Wilm's Tumour in Sudan 1992. Abstract Book of Postgraduate Medical Board of Khartoum University, Khartoum University, Khartoum, 77.

[12] Rogers, T., Bowley, D.M., Poole, J., Swanepoel, P., Wainwright, J., Beale, P. and Pitcher, G. (2007) Experience and Outcomes of Nephroblastoma in Johannesburg, 1998-2003. European Journal of Paediatric Surgery, 17, 41-44.

[13] Abdallah, F.K., Macharia, W.M. (2001) Clinical Presentation and Treatment Outcome in Children with Nephroblastoma in Kenya. East African Medical Journal, 78, S43-S47.

[14] Beckwith, J.B. and Palmer, N.F. (1978) Histopathology and Prognosis of Wilm's Tumour Results from the first National Wilm's Tumour Study. Cancer, 41, 1937-1948. https://doi.org/10.1002/1097-0142(197805)41:5\%3C1937::AID-CNCR2820410538\% 3E3.0.CO;2-U

[15] Salih, H.M. (2015) Clinical Presentation and Histopathological Pattern of Wilm's Tumour among Sudanese Patients in Khartoum 2006-2010. Doctoral Dissertation, University of Khartoum, Khartoum.

[16] Fadoo, Z., Hussain, S., Panju, S. and Alvi, S. (2009) Kidney Tumours in Children: A Single Centre Experience from a Developing Country. Turkish Journal of Cancer, 39, 133-137.

[17] Green, D.M., Beckwith, J.B., Breslow, N.E., Faria, P., Moksness, J., Finklestein, J.Z., Grundy, P., Thomas, P.R., Kim, T. and Shochat, S. (1994) Treatment of Children with Stages II to IV Anaplastic Wilm's Tumour: A Report from the National Wilm's Tumour Study Group. Journal of Clinical Oncology, 12, 2126-2131. https://doi.org/10.1200/JCO.1994.12.10.2126

[18] Green, D.M. (2004) The Treatment of Stages I-IV Favourable Histology Wilm's Tumour. Journal of Clinical Oncology, 22, 1366-1372. https://doi.org/10.1200/JCO.2004.08.008

[19] Pelletier, J., Nakagama, H. and Housman, D.E. (1996) The Molecular Genetics of Wilm's Tumour. In: Mihich, E. and Housman, D., Eds., Cancer Genes, Springer, Boston, 103-121. https://doi.org/10.1007/978-1-4615-5895-8 6

[20] Uba, A.F. and Chirdan, L.B. (2007) Childhood Wilm's Tumour: Prognostic Factors in North Central Nigeria. West African Journal of Medicine, 26, 222-225. 
https://doi.org/10.4314/wajm.v26i3.28314

[21] Ruteshouser, E.C., Robinson, S.M. and Huff, V. (2008) Wilm's Tumour Genetics: Mutations in WT1, WTX, and CTNNB1 Account for Only about One-Third of Tumours. Genes, Chromosomes and Cancer, 47, 461-470.

https://doi.org/10.1002/gcc.20553 